\title{
Innovation Practice and Development Strategy of Industry-University- Research Cooperation of Universities -Taking Beihang University as the Example
}

\author{
Lige Zhang ${ }^{1, ~ a, ~ J i a n g ~ Z h a n g ~}{ }^{2, ~ b, *}$, Jing Zhao ${ }^{1, c}$ \\ ${ }^{1}$ Institute of Science and Technology, Beihang University, Beijing100191, China \\ 2Party and Government Office, Beihang University, Beijing100191, China \\ azhanglige@buaa.edu.cn, bzhangjiang@buaa.edu.cn, 'zhao_jing@buaa.edu.cn
}

\begin{abstract}
Keywords: university; industry-university-research cooperation; innovation practice; development strategy.
\end{abstract}

\begin{abstract}
Industry-university-research cooperation is an important way to serve the community and national economic development, and it promotes the development and transformation of technology to productivity of universities effectively. As the main force of technological innovation, universities need to improve the operational mechanism of industry-university-research cooperation constantly in order to adapt to the new situation that the enterprises are the main innovation body, and support the national technology innovation system. Taking Beihang University as the example, development strategy and innovation practice of industry-university-research cooperation were introduced. Reflections on how to accelerate the integration and development of industry-university-research cooperation are given.
\end{abstract}

\section{Introduction}

University is the main force of promoting technological progress and innovation. Propelling the industry-university-researchis not only the urgent needs of the national economic and social development, but also the internal demand to promote the development of university. Industry university-research cooperation is the key way to the implementation of social responsibility and the education quality of university ${ }^{[1][2]}$. As a research university of multidisciplinary and open mode, Beihang university has distinct feature of aeronautics and astronautics, and engineering and technical advantages, and it always insistson putting the industry-university-research strategy in important position.In recent years, Beihang response the national sragety such as the Belt and Road, Integration of Beijing-Tianjin-Hebei and Civil-Military integration positivey, and it formulate policies to strengthen the supply of science and technology and lead researchers to write scientific papers on the land of the motherland. So the scientific and technological achievements can serve the national economic construction more directly. Facing the demand of industrial and regional economic development, Beihang explores the potential of industry-university-research cooperation, and promotes cooperation between schools-enterprises, schools-local governments vigorously. Beihang has been working to achieve the advantages of major scientific research achievements into the real productive forces that are effective in promoting industrial innovation.

\section{Beihang'sinnovation and practice in industry-university-research cooperation}

\subsection{Beijing Beihang Advanced Industrial Technology Research Institute was Established Aiming To Promotie Industrial and Technological Innovation}

In September 2010, Beijing Beihang Advanced Industrial Technology Research Institutewas established by Beijing govenment and Beihangjointly. Research institute's main body is Beihang university, and it is operated as enterprises. Its main tasks include transforming and industrialization of major scientific and technological achievements; undertaking major research and development projects; and incubating innovative enterprises. Research institute established the joint operation mechanism by Beihang science and technology management, Beihang National University Science 
Park and Beijing Beihang Advanced Industrial Technology Research Institute co., LTD. This model enables research institute to be able to undertake the functions of the relevant internal organs of the university, and also have the ability to carry out the industrialization of science and technology. In order to promote the transformation of major scientific and technological achievements, research institute has developed series management methods for the transformation and technology transfer with Beihang characteristics. Encouragement scheme of the stock option that establishing enterprise with the full intangible asset was first developed, and the industrialization of 'laser rapid prototyping technology of titanium alloy structure' was carried out.Research institute set up CATIC laser Co., Ltd. with Avic Heavy Mac Chinery co., LTD. and Beijing govenment. The whole process of technology transfer and equity incentive was completed, and the complete path of the technology investment was formed. Combined with Xian Flight Automatic Control Research Institute, research institute established Aviation Gyro(Beijing) Photo electricity Technology Co Ltd., and it undertookthe implementation of industrialization project of the fiber optic gyroscope. In 2013, Ministry of science and technology major scientific instruments and equipment development 'development and application of the optical polarization axis and the end face shape on-line test instrument ' was undertook by Beihang and Aviation Gyro(Beijing) Photo electricity Technology Co Ltd., and the Funding was 6637.65 million.

\subsection{Implementing advanced Industrial Partnership Plan and Foster New Growth Areas for Research and Development}

Facing the need of the national major strategic and around the special advantage of aviation and aerospace and information, Beihang carried out'the advanced industrial partnership project' aiming to deepen the cooperation with large enterprises. Beihang has signed cooperation agreements on collaborative innovation with large companies such as Aviation Industry Corporation of China, China Aerospace Science \& Industry Corp., China Aerospace Science \& Technology Corp.and Commercial Aircraft Corporation of China, Ltd ...Beihang and Beijing science and technology commission have signed a cooperation agreement on aviation, space and information, and will receive 50 million yuan in support from Beijing each year. On the other hand, Beihang has established more than 73 schoolenterprise cooperation laboratories with industry leader enterprises such as LENOVO, BAIC Group and so on, and it provided an effective platform for deep cooperation between university and enterprise. In order to carry out cutting-edge technological breakthroughs, industry-universityresearch innovation fund was set up with HUAWEI, SAMSUNG and other enterprises. Industries technical innovation alliance such as 'National General Aviation Industry Cooperation Innovation Alliance', 'China Cloud Industry Alliance', 'Intelligent Urban Industrial Technology Innovation Alliance' and other alliances were established. Advanced industrial partnership plan effectively improved the cooperation tightness between Beihang and related industry advantage enterprises, widen the cooperation channels, and supported the school scientific research work.

\subsection{Promote Collaborative Innovation Actively and Create a New Pattern of Industry- University-Research Innovation}

The implementation of collaborative innovation program was promoted actively, and collaborative innovation centers of school level involving aviation, aerospace, information, biology, instruments were established. Collaborative innovation center of advanced aero-engine was one of the 14 collaborative innovation centers identified by the '2011 plan 'of Ministry of Education of the People's republic of China in the first round. Collaborative innovation center of advanced aero-engine is led by Beihang and Aviation Industry Corporation of China. Northwestern Polytechnic University and Nanjing university of Aeronautics and Astronautics are on the core collaborative layer, and Institute of Engineering Thermophysics of Chinese Academy of Science and universities of Ministry of Education of the People's Republic of China are on the outer layer. The system mechanism, organization and management rules were established based on virtual share-holding system. Large aircraft collaborative innovation center, composite aircraft collaborative innovation centerand spin electronic collaborative innovation center led by Beihangwere replied by Ministry of Industry and information Technology of the People's Republic of China. 
In order to promote the construction of collaborative innovation center, Beihang has introduced series of management measures and documents such as 'operation management measure of collaborative innovation center (trial)', 'detailed rules of talent zone for the implementation (trial)', 'collaborative research and scientific research organizations rules of collaborative innovation center of advanced aero-engine' and so on. Collaborative innovation system, direction and goals were determined, and collaborative innovation vitality was enhanced significantly. Research base sharing and effective integration of talent, equipment, achievement, and information were realized between universities and institutes. So that the research of individual workshops in universities evolved into a nationally organized and coordinated systematic study, which effectively promoted the simultaneous improvement of school personnel, subject and scientific research ability.

\subsection{Set up Cooperation Platform Between University and Local Government, and Explore New Modes of Serving Area Economy}

Beihang actively works with the national key regional economic center. Combining with the local industry development needs, Beihang support regional economic development through setting up cooperation platform. It has established comprehensive strategic cooperative relations with more than 20 provinces, including Beijing, Hebei, Anhui, Liaoning, Yunnan, Jiangxi and Qingdao, etc. Around some key areas such as aerospace, information technology, Internet of things and wisdom city, Beihangestablished more than 10 school cooperation platforms successively in Yangtze River delta, Pearl River delta, and Bohaibay area.

Taking Guangzhou, Shenzhen, and Shunde as the center, Beihang advanced technology southern industrial base was founded. Beihang (Wenzhou) institute was constructed around the industry need of Wenhzou. Beihang(danyang) aerospace industry research institute was established, and Danyang aerospace industry academician's workstation was established. Jiangxi beihang aerospace industry base and Beihangjiangxi navigation research institute were built jointly with Nanchang city government. Dongguan Beihang institute was established jointly with Dongguan govenment. Beihang (tianjinwuqing) intelligent manufacturing research institutewas jointly constructed with the government of the wuqing district of tianjin.In 2016, a new chapter was opened in cooperation between Beihang and local govenment. Beihang Qingdao institute and branch lab of state key laboratory of virtu reality of technology and system of Beihang were set up in Qingdao, and information technology, marine environment, intelligent manufacture are the key research direction. Working with Hangzhou, Beiang built Hangzhou campus of Beihang and the town of aeronautics and space. Together with Hefei, Beihang Hefei science city project started up, and it would focus on scientific research, achievements transformation, high-end education and international exchange.Together with Chengdu, Beihang built Beihang west international innovation port, Beihang Chengdu aerospace engine research institute and Beihang Chengdu aviation power innovation research institute. Relying on Beijing high-tech center, Beihang medical engineering cross innovation institutewas built jointly with Fangshan District, and it aims to promote the comprehensive development of medical engineering cross innovation and integration. The construction of university -local government cooperation platform has effectively promoted the transformation of the scientific and technological achievements of Beihang, enhanced the capacity of Beihang to serve the regional economy and expanded the influence of Beihang brand.

\subsection{Build Beijing Advanced Industrial Technology Research Institute and Explore New Models for The Integration of Science and Technology Industries}

In order to deepen the reform of science and technology system, implement the innovation-driven development strategy, give full play to the decisive role of the market in the allocation of resources, Beijing Advanced Industrial Technology Research Institute was built jointly by Beihang, Beijing Municipal Science and Technology Commission, Zhongguancun Administrative Committee, and Haidian District People's Government.In view of the strategic needs of national science and technology development, combined with the current strategic emerging industry development status and layout, Research Institute adhere to the principles of 'demand from the enterprise, cultivating technology from source, government policy support, incubating technological achievements together'. It is exploring an open, converged and diverse innovation model driven by government, university, 
business and capital and trying to get through the last mile from technology to industry. Research institute will set up innovation centersin key areas such as laser material manufacturing, aeroengine, spin electronics, large data, organic optoelectronic materials, etc., aiming to break through the bottleneck of technology to industrial development and serve the economic and social development of the capital.

In August 2014, research Institute successfully held the 'Beijing innovation and entrepreneurship seminar and the first new technology conference of Beijing Advanced Industrial Technology Research Institute'. 13 new technologies were released, and the formation of cooperative funds was disussed by Zhongguancun Administrative Committee, Haidian District People's Government and alumnus. Research institute successfully promoted operation of Jiangxi Haikong Xing Helicopter Technology Co., Ltd. and Beijing Institute of Materials Technology Co., Ltd. Now it is preparing to introduce external investment, create the entitiy of camera-type millimeter wave human body detection technology, and accelerate the industrialization of scientific and technological achievements process.

\section{Development Strategy}

\subsection{Improve the Incentive and Evaluation Mechanism to Stimulate Endogenous Motivation}

Influenced by traditional concepts, college teachers' enthusiasm engaging industry- university research cooperation is not high. It is necessary to stimulate the endogenous power of the industryuniversity-research cooperation from the incentive and evaluation mechanism ${ }^{[3][4]}$. In the cooperation between university and enterprises, from simple horizontal cooperation of science and technology to deep-level cooperation such as establish laboratory jointly, a series of incentives should be developed to encourage teachers to carry out various forms of cooperation with enterprises, such as raising the labor costs proportion of cross-subject, allocating graduate enrollment indicators for universityenterprise laboratory. In the cooperation between university and local government, hematopoietic function of the university-local government cooperation institute should be strengthened and policy environment should be established to encourage teachers to develop in the cooperation institute. Such as encouraging teachers to bear full-time work of the institute and university retains their school retirement treatment; considering the subject and funding, intellectual property and incentives, income of industrial technology transfer obtained in the institute into the school performance appraisal system and so on. In terms of achievement transformation, the proceeds of the inventors should be raised and classification evaluation system needs to be developed for researchers engaging in achievement transformation.

\subsection{Improve the Achievement Transformation Mechanism and Smooth the Conversion Path}

As one of the pilot units of scientific and technological achievements use, disposal and revenue management reform in the central level institutions, Beihang has introduced management approaches and provide policy basis for achievement transformation. In the next step, Beihang will improve the operability of transformation mechanism as soon as possible. In order to transfer scientific research to the enterprise and realize its industrialization effectively, professional team would be equipped, specialized achievements incubation mechanism would be the established, and venture capital funds would be established. The introduction of the corresponding implementation details and operational procedures should speed up, including patent transfer, licensing and pricing process, achievement adult equity incentives and so on ${ }^{[5]}$.

\subsection{Strengthen the Integration of Military and Civilian Development, and Build a Platform for Integration of Military and Civilian Integration}

It is necessary to strengthen the integration of military and civilian development, and crack bottleneck problemsin the process of integration. Interaction and resource sharing mechanismof integration of civil and military should be establishedas soon as possible, and the corresponding security system and incentive policies should be completed constantly. Beihang will play the advantages of serving national defense around the common technology of weapons equipment and civilian products such as the new unmanned aerial vehicles, intelligent robots, new materials, new energy and so on, and innovateindustry-university-research cooperation model. Through constructing 
cooperation platform with local government and enterprises, establishing military and civilian integration think tank and other means, the implementation of military technology is promotedin the civilian field, and appropriate civilian technology is exploredin military field. Effective integration and collaborative innovation of the military and civilian technology will enhance Beihang's ability of serving the country's major needs.

\section{Conclusion}

In the situation that enterprises is the main body of innovation, industry-university-research cooperation has become an important way to promote technological innovation, industrial transformation and upgrading and economic development. As a research university with distinctive industrial characteristics, Beihang will continue to practice the strategy of industry-universityresearch cooperation in-depth, deepen the reform of science and technology system, and adhere to facing the national economic construction strategy needs. Aiming at strategic emerging industries, combining with industrial development needs, Beihang will transform the advantages and innovation capacity into the real productive forces serving industry and regional development successfully and make greater contributions for the country's economic and social development.

\section{References}

[1]. GuangyinGuo. Industry-University-Research Cooperation: AnImportant Mission of Higher Education Institutions [J]. QiuShi,2012(1):59-61

[2]. Xiaofeng Wang, Lianjun Wang, Yong Qi. InnovateIndustry-University-Research Cooperation andService Economic and Social Development [J]. Chinese University Science \& Technology, 2011(12):8-10

[3]. Yan Ding, Qingming Zhou. Industry-University-Research Cooperation in Developed Countries:Experience and Inspiration[J].China Agricultural Education, 2014(2): 5-8

[4]. Xunsheng Zhou. The Practics and Mode Innovation of University-Industry Colaboration.Journal of Taiyuan University of Technology(Social Sciences Edition),2012,30(4):8-71

[5]. XingminGao, Xiangjun Zhang. Research on Endowment Effect and Profits Allocation of University-Industry-Science Partnership [J]. Science \& Technology Progress and Policy, 2015(5):15-19 